\title{
Effectiveness of early initiation of antiretroviral therapy in adults with HIV associated tuberculosis in Lesotho in 2012
}

\author{
Maletsatsi Lenela* (iD and Stephen Knight ${ }^{a}$ \\ ${ }^{a}$ Discipline of Public Health Medicine, School of Nursing and Public Health, University of KwaZulu-Natal \\ *Corresponding author, email:mlenela@gmail.com
}

Background: Lesotho has a huge burden of human immunodeficiency virus associated tuberculosis (HIV-TB). In this study we compared the effectiveness of early versus late commencement of antiretroviral therapy (ART) in adults living with HIV-TB in Lesotho.

Methods: Three out of 17 hospitals were randomly selected and data extracted from the hospitals' tuberculosis (TB) treatment registers for 247 adults living with HIV-TB who completed TB therapy during the first quarter of 2012.

Results: Eighty (32\%) commenced ART early (<4 weeks), 100 (41\%) were started late ( $\geq 4$ weeks) and 67 (27\%) received no ART. Both early and late ART initiators were more likely to have a successful TB outcome (Adjusted Odds Ratio (AOR) 10.1, 95\% Cl: 3.7 - 27.5 and AOR 8.4, 95\% Cl: 3.4 - 20.6, respectively) relative to the group who had no ART ( $p<0.001)$.

Conclusions: Effective treatment exists for managing HIV-TB simultaneously. The guidelines for initiation of ART in adult HIV-TB in Lesotho have not been fully implemented, but those who commenced ART had significant clinical benefits. Health departments must address the challenges encountered in treating HIV-TB simultaneously to ensure those co-infected receive optimal care.

Keywords: low income country, tuberculosis treatment

\section{Introduction}

Human immunodeficiency virus associated tuberculosis (HIV-TB) is the leading cause of death in Africa. Tuberculosis (TB) accounts for approximately $25 \%$ of all HIV-TB deaths. ${ }^{1}$ The number of those HIV-TB co-infected continues to grow rapidly and poses a serious public health challenge in sub-Saharan Africa. ${ }^{2}$ An epidemic of TB commenced in Lesotho in 1985, matching the HIV and acquired immune deficiency syndrome (AIDS) epidemics closely. ${ }^{3}$ Lesotho has been greatly affected by HIV-TB, negatively impacting the economically active and overburdening health

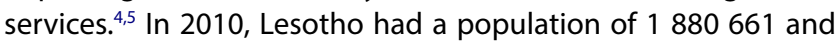
13520 cases of TB (719 per 100000 people), of which $76 \%$ were HIV-TB co-infected. ${ }^{4}$

Mortality in HIV-TB occurs due to complications from TB disease, impaired immunity from advancing AIDS and adverse treatment effects. ${ }^{6}$ Effective treatments for TB and HIV exist but treating both diseases simultaneously is clinically challenging. ${ }^{7}$ World Health Organisation (WHO) guidelines are available that support HIV-TB co-treatment. The guidelines are supported by evidence that HIV-TB treatment integration is essential for improved survival and that earlier antiretroviral therapy (ART) initiation is necessary. Early ART reduced mortality among patients with baseline $\mathrm{CD}^{+} \mathrm{T}$-cell counts $<50$ cells $/ \mathrm{mm}^{3}$, but no mortality benefit was found for those with counts $>50$ cells $/ \mathrm{mm}^{3}$. Early ART doubled the risk for TB-associated immune reconstitution inflammatory syndrome (IRIS), regardless of patients' $\mathrm{CD} 4^{+} \mathrm{T}$-cell counts. $^{8}$

Despite evidence from clinical trials, ART initiation is often delayed until TB treatment (TBT) completion due to potential drug interactions, similar and overlapping side effects, nonadherence due to high pill burden, IRIS and programmatic challenges. Deferred ART initiation in HIV-TB may result in AIDSrelated illness and death. The risks and benefits of poor TB outcomes associated with delaying ART initiation, against the problems associated with early ART initiation after starting TBT, need to be evaluated. ${ }^{7}$

In 2011, the Lesotho National Antiretroviral Therapy guidelines for integrated HIV-TB treatment and care were revised in line with the WHO guidelines, which recommend initiating ART within two weeks of starting TBT if the CD4 ${ }^{+}$T-cell count is $<50$ cells $/ \mathrm{mm}^{3}{ }^{3}$ Previously, ART initiation in Lesotho was based on a $\mathrm{CD}^{+}$T-cell count of $<200$ cells $/ \mathrm{mm}^{3}$, leading to poor clinical outcomes as a more limited number of the sick patients benefitted from ART. In addition, the HIV-TB services were not user-friendly as care could not be accessed under one roof. This study compares the effectiveness of 'early' ( $<4$ weeks) versus 'late' ( $\geq 4$ weeks) commencement of ART in adults living with HIV-TB, based on TB outcomes, in Lesotho in 2012.

\section{Methods}

An observational and analytical cross-sectional study design was used. The study population included HIV positive adults (>15 years) with proven and empiric TB (both pulmonary and extra-pulmonary) during the first quarter of 2012. The study was conducted in three randomly selected hospitals in Lesotho.

The study sample comprised 247 patients. Data was extracted from hospital TBT registers and TBT cards and recorded onto a customised data form by the principal investigator. Consecutive patients were included until the targeted number of patients had been obtained. Standard WHO TB treatment outcomes were collected for all participants. The independent variables included patient age, sex, type of TB (new patient or retreatment), site of $\mathrm{TB}, \mathrm{CD} 4^{+} \mathrm{T}$-cell counts, timing of ART initiation and hospital where the patient was registered.

Data was summarised with frequency distribution tables using SPSS. To control for confounding, stratification and multivariable models were considered. For the analysis the timing of initiation 
Table 1: Timing of ART initiation in adults living with HIV-TB in three hospitals, by type and site of TB, CD4+ T-cell count, and age in Lesotho, 2012

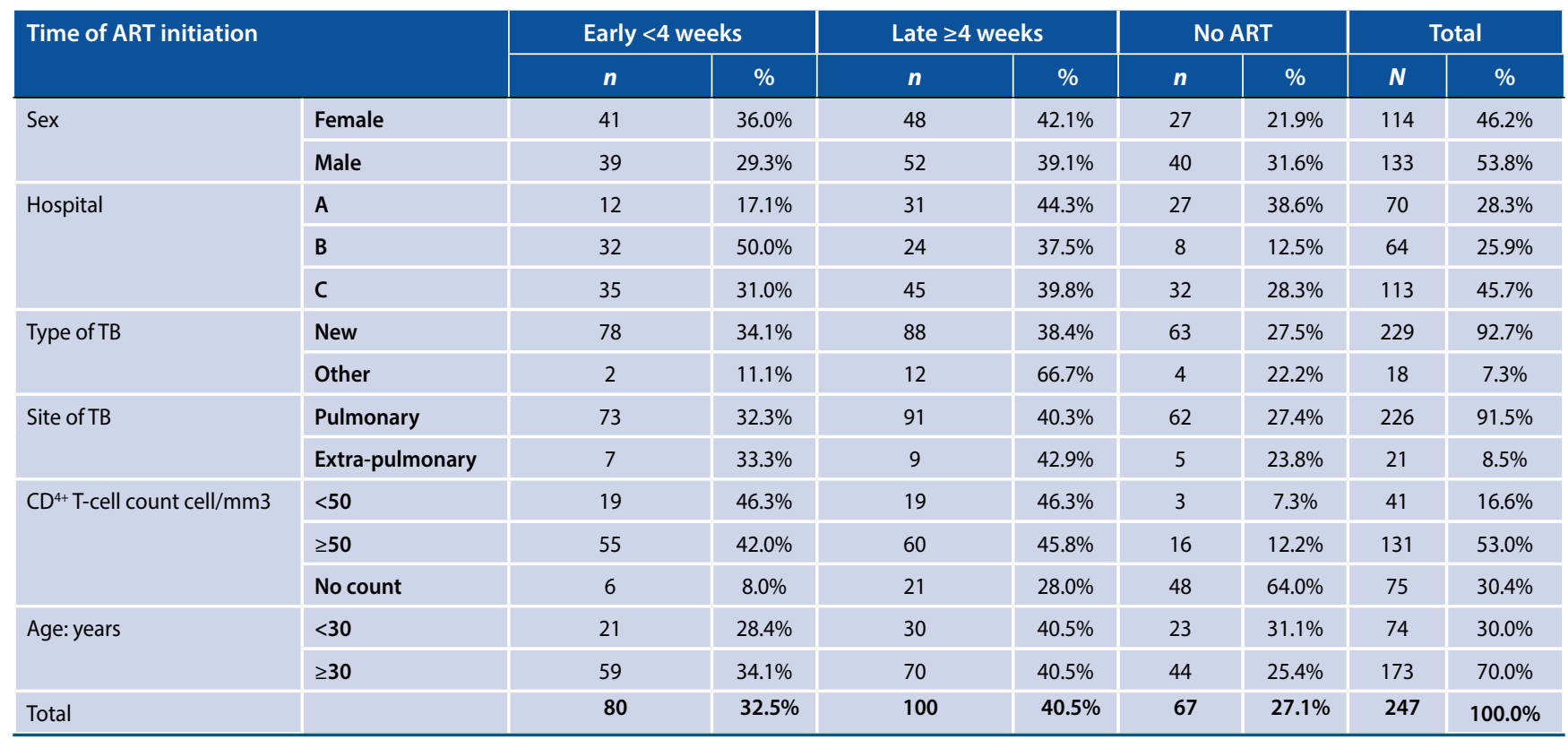

Notes: ART refers to antiretroviral therapy, TB refers to tuberculosis and HIV refers to human immunodeficiency virus.

Table 2: TB treatment outcomes and prevalence ratios (PR) for different stages of ART initiation in people living with HIV-TB in three hospitals in Lesotho, 2012

\begin{tabular}{|c|c|c|c|c|c|c|c|c|}
\hline \multirow{2}{*}{$\begin{array}{l}\text { Treatment } \\
\text { Outcomes }\end{array}$} & \multicolumn{2}{|c|}{$\begin{array}{c}\text { Early } \\
<4 \text { weeks }\end{array}$} & \multicolumn{2}{|c|}{$\begin{array}{c}\text { Late } \geq 4 \\
\text { weeks }\end{array}$} & \multicolumn{4}{|c|}{ Total } \\
\hline & $n$ & $\%$ & $n$ & & $n$ & $\%$ & $n$ & $\%$ \\
\hline Cured & 12 & $15.0 \%$ & 23 & $23.0 \%$ & 7 & $10.4 \%$ & 42 & $17 \%$ \\
\hline Completed & 54 & $67.5 \%$ & 58 & $58.0 \%$ & 22 & $32.8 \%$ & 134 & $54.3 \%$ \\
\hline Successful & 66 & $82.5 \%$ & 81 & $81.0 \%$ & 29 & $43.3 \%$ & 176 & $71.3 \%$ \\
\hline Died & 5 & $6.3 \%$ & 6 & $6.0 \%$ & 15 & $22.4 \%$ & 26 & $10.5 \%$ \\
\hline Defaulted & 9 & $11.3 \%$ & 11 & $11.0 \%$ & 22 & $32.8 \%$ & 42 & $17.0 \%$ \\
\hline Failed & 0 & $0.0 \%$ & 2 & $2.0 \%$ & 1 & $1.5 \%$ & 3 & $1.2 \%$ \\
\hline Total & 80 & $32.4 \%$ & 100 & $40.4 \%$ & 67 & $27.1 \%$ & 247 & \\
\hline
\end{tabular}

Notes: Successful Outcome $=$ Cured + Completed treatment.

TOTAL $=$ Successful + Died + Defaulted + Failed.

of TBT was categorised as 'early' ( $<4$ weeks) and 'late' ( $\geq 4$ weeks). The CD4 ${ }^{+}$T-cell counts were grouped as $<50$ and $\geq 50$ cells $/ \mathrm{mm}^{3}$.

Ethical approval was obtained from the University of KwaZuluNatal Biomedical Research Ethics Committee (BE 300/12) and the Lesotho Research Coordinating Unit. Permission to conduct and collect the data was obtained from each hospital manager.

\section{Results}

There were 247 participants with HIV-TB, enrolled in the study, of which 180 (73\%) participants were commenced on ART, 80 (44\%) early ( $<4$ weeks) and $100(56 \%)$ late ( $\geq 4$ weeks) after having commenced TBT.

One hundred and fourteen (46\%) were females, and a greater proportion of females (76\%; 95\% Cl: 67 - 84) accessed ART. More males than females ( $32 \%$ vs $22 \%$ ) were not started on ART (Table 1).
Seventy percent of the study sample was $\geq 30$ years old, $92 \%$ had pulmonary TB and $93 \%$ were receiving TBT for the first time. Only $172(70 \%)$ had a CD4+ ${ }^{+}$-cell count result recorded in the TBT register, and $17 \%$ of these counts were less than 50 cells $/ \mathrm{mm}^{3}$ (Table 1). In those who had a CD4 ${ }^{+} \mathrm{T}$-cell count, the proportion of those commencing ART early and late was similar. The majority (64\%) of those who did not have a CD4 ${ }^{+} \mathrm{T}$-cell count were, however, not started on ART (Table 1). One hospital commenced ART in $88 \%$ of those with HIV-TB, with a higher proportion (50\%) commencing ART early.

A similar proportion of the participants had a successful (cured or completed TBT) TB outcome $-83 \%$ in the early initiators and $81 \%$ in the late initiators (Table 2).

The overall case-fatality was $11 \%$, but was highest (22\%) in those not on ART and 6\% in both groups who were on ART (Table 2). Case-fatality was highest in those without a $\mathrm{CD} 4^{+} \mathrm{T}$-cell count (17\%) followed by those with a CD4 ${ }^{+} \mathrm{T}$-cell count $<50$ cells $/ \mathrm{mm}^{3}$ (15\%), and lowest in those with CD4 ${ }^{+} \mathrm{T}$-cell count $\geq 50$ cells $/ \mathrm{mm}^{3}$ (5\%) (Table 3). In all of these groups, those with HIV-TB fared worst (died, failed or defaulted) if not on ART (Table 3).

Successful TB outcomes were substantially better in all groups who commenced ART relative to those who did not (AOR 6.2, $95 \% \mathrm{Cl}: 3.7-27.5$ and AOR 5.6, 95\% Cl: 2.8 - 11.2, respectively) ( $p<$ 0.001) (Table 4).

\section{Factors associated with TB treatment outcomes}

After the bivariate regression, some predictors, namely hospital, CD4 ${ }^{+}$T-cell count and both stages when initiated on ART (early $<4$ weeks and late $\geq 4$ weeks) remained significant and, therefore, were included into the multivariable analysis. Age and sex by virtue of being confounders were also included into the multivariable model even though they were not significant. In the final model, hospital (AOR $0.4,95 \% \mathrm{Cl}: 0.2-1.0$ ) and stage when initiated on ART (early AOR 10.1, 95\% Cl: $3.7-27.5$ and late AOR 8.4, 95\% Cl: 3.4 - 20.6) were the predictors that remained statistically significant ( $p=0.040$ and $p<0.001$, respectively). 
Table 3: Successful TB outcomes by stage of ART Initiation, hospital, age, sex, CD4 ${ }^{+}$T-cell count, site of TB and type of TB for adults living with HIV-TB in three hospitals in Lesotho, 2012

\begin{tabular}{|c|c|c|c|c|c|c|c|c|c|c|}
\hline & & Successful & Total & \multirow[t]{2}{*}{ Prevalence } & \multicolumn{3}{|c|}{ Unadjusted Odds Ratio } & \multicolumn{3}{|c|}{ Adjusted Odds Ratio } \\
\hline & Predictor & & & & AOR & $95 \% \mathrm{Cl}$ & $p$-value & AOR & $95 \% \mathrm{Cl}$ & $p$-value \\
\hline \multirow[t]{2}{*}{ Age } & $\geq 30$ years & 122 & 173 & $70.5 \%$ & Ref. & & & & & \\
\hline & $<30$ years & 54 & 74 & $73.0 \%$ & 1.1 & 0.6 to 2.1 & 0.70 & 0.6 & 0.3 to 1.3 & 0.21 \\
\hline \multirow[t]{3}{*}{ Hospital } & A & 50 & 64 & $78.1 \%$ & Ref. & & & & & \\
\hline & B & 73 & 113 & $64.6 \%$ & 0.9 & 0.4 to 1.9 & 0.7 & 0.4 & 0.2 to 1.0 & 0.04 \\
\hline & $C$ & 53 & 70 & $75.7 \%$ & 0.5 & 0.3 to 1.0 & 0.1 & 0.6 & 0.2 to 1.6 & 0.33 \\
\hline \multirow[t]{2}{*}{ Sex } & Male & 97 & 133 & $72.9 \%$ & Ref. & & & & & \\
\hline & Female & 79 & 114 & $69.3 \%$ & 0.8 & 0.5 to 1.5 & 0.5 & 1.4 & 0.7 to 2.6 & 0.29 \\
\hline \multirow[t]{2}{*}{ Site of TB } & Pulmonary & 159 & 226 & $70.4 \%$ & Ref. & & & & & \\
\hline & Extra-PTB & 17 & 21 & $81.0 \%$ & 1.8 & 0.6 to 5.5 & 0.3 & - & - & - \\
\hline \multirow[t]{2}{*}{ Type of TB } & Repeat & 11 & 18 & $61.1 \%$ & Ref. & & & & & \\
\hline & New & 165 & 229 & $72.1 \%$ & 0.6 & 0.2 to 1.6 & 0.3 & - & - & - \\
\hline \multirow[t]{3}{*}{$\mathrm{CD}^{+}$count } & Unknown & 47 & 75 & $62.7 \%$ & & & & & & \\
\hline & $<50$ & 29 & 41 & $70.7 \%$ & Ref. & & & & & \\
\hline & $\geq 50$ & 100 & 131 & $76.3 \%$ & 1.1 & 0.3 to 1.7 & 0.0 & 0.7 & 0.3 to 1.7 & 0.42 \\
\hline \multirow{3}{*}{$\begin{array}{l}\text { Stage ART } \\
\text { initiated }\end{array}$} & No ART & 29 & 67 & $43.3 \%$ & Ref. & & & & & \\
\hline & $\begin{array}{l}\text { Early } \\
\text { (<4 weeks) }\end{array}$ & 66 & 80 & $82.5 \%$ & 6.2 & 2.9 to 13.1 & 0 & 10.1 & 3.7 to 27.5 & $<0.001$ \\
\hline & $\begin{array}{l}\text { Late ( } \geq 4 \\
\text { weeks) }\end{array}$ & 81 & 100 & $81.0 \%$ & 5.6 & 2.8 to 11.2 & 0 & 8.4 & 3.4 to 21.0 & $<0.001$ \\
\hline TOTAL & & 176 & 247 & $71.3 \%$ & & & & & & \\
\hline
\end{tabular}

Table 4: TB Treatment outcomes by CD4 ${ }^{+} \mathrm{T}-$-Cell count and ART Initiation in Lesotho, 2012

\begin{tabular}{|c|c|c|c|c|c|c|c|}
\hline & \multicolumn{2}{|c|}{$\begin{array}{l}\text { Successful TB } \\
\text { Outcome }\end{array}$} & \multicolumn{2}{|c|}{ Died } & \multicolumn{2}{|c|}{$\begin{array}{l}\text { Default \& } \\
\text { failed }\end{array}$} & \multirow[t]{2}{*}{ Total } \\
\hline & No. & $\%$ & No. & $\%$ & No. & $\%$ & \\
\hline \multicolumn{8}{|c|}{$\begin{array}{l}\mathrm{CD}^{+}<50 \text { cells/ } \\
\mathrm{mm}^{3}\end{array}$} \\
\hline No ART & 0 & $0.0 \%$ & 1 & $33.3 \%$ & 2 & $66.7 \%$ & 3 \\
\hline $\begin{array}{l}\text { Early } \\
\text { ART }\end{array}$ & 14 & $73.7 \%$ & 2 & $10.5 \%$ & 3 & $15.8 \%$ & 19 \\
\hline $\begin{array}{l}\text { Late } \\
\text { ART }\end{array}$ & 16 & $84.2 \%$ & 3 & $15.8 \%$ & 0 & $0.0 \%$ & 19 \\
\hline $\begin{array}{l}\mathrm{CD}^{+} \\
\geq 50 \\
\text { cells/ } \\
\mathrm{mm}^{3}\end{array}$ & 30 & $73.2 \%$ & 6 & $14.6 \%$ & 5 & $12.2 \%$ & 41 \\
\hline No ART & 6 & $37.5 \%$ & 3 & $18.8 \%$ & 7 & $43.8 \%$ & 16 \\
\hline $\begin{array}{l}\text { Early } \\
\text { ART }\end{array}$ & 45 & $83.3 \%$ & 2 & $3.7 \%$ & 7 & $13.0 \%$ & 54 \\
\hline $\begin{array}{l}\text { Late } \\
\text { ART }\end{array}$ & 49 & $80.3 \%$ & 2 & $3.3 \%$ & 10 & $16.4 \%$ & 61 \\
\hline $\begin{array}{l}\text { No } \\
\mathrm{CD}_{4}^{+}\end{array}$ & 100 & $76.3 \%$ & 7 & $5.3 \%$ & 24 & $18.3 \%$ & 131 \\
\hline No ART & 23 & $47.9 \%$ & 11 & $22.9 \%$ & 14 & $29.2 \%$ & 48 \\
\hline $\begin{array}{l}\text { Early } \\
\text { ART }\end{array}$ & 5 & $83.3 \%$ & 1 & $16.7 \%$ & 0 & $0.0 \%$ & 6 \\
\hline \multirow{2}{*}{$\begin{array}{l}\text { Late } \\
\text { ART }\end{array}$} & 18 & $85.7 \%$ & 1 & $4.8 \%$ & 2 & $9.5 \%$ & 21 \\
\hline & 46 & $61.3 \%$ & 13 & $17.3 \%$ & 16 & $21.3 \%$ & 75 \\
\hline Total & 176 & $71.3 \%$ & 26 & $10.5 \%$ & 45 & $18.2 \%$ & 247 \\
\hline
\end{tabular}

\section{Discussion}

This study describes the TB outcomes of HIV-TB co-infected patients in a low income country. In sub-Saharan Africa, up to $75 \%$ of patients are HIV-TB co-infected. ${ }^{9}$ The prevalence of HIV in Lesotho in 2010 was $23 \%$, and $76 \%$ of those were co-infected. ${ }^{4}$ This is very similar to reports from South Africa ( $11 \%$ and $65 \%$, respectively) and other low income countries in the region. ${ }^{10}$

Lesotho has introduced evidence-informed treatment guidelines for effectively treating TB and HIV simultaneously, which is similar to the policy in South Africa. ${ }^{11}$ Thus, both Lesotho and South Africa have adopted WHO guidelines indicating that HIV-TB patients should be initiated on ART within two weeks if $\mathrm{CD}^{+}$ T-cell count is $<50$ cells $/ \mathrm{mm}^{3}$. Three quarters of those with HIV-TB commenced ART, but only one third were initiated early in contrast to a hospital-based Durban study where $66 \%$ initiated ART early. ${ }^{12}$

About two thirds (70\%) of participants had a recorded CD4 ${ }^{+}$T-cell count, substantially less than that reported in Durban, South Africa, where $99 \%$ of those co-infected had a recorded CD4 ${ }^{+}$ T-cell count. ${ }^{12}$ However, the South African study was based in a relatively well-resourced urban 'pilot' ART initiation site.

The successful TB outcomes and case-fatality were similar whether initiated on ART early or late. Although 'early' commencement in this cohort was not exactly according to WHO policy (within two weeks if $\mathrm{CD}^{+} \mathrm{T}$-cell count $<50$ cells/ $\mathrm{mm}^{3}$, or within eight weeks if CD4 ${ }^{+} \mathrm{T}$-cell count $>50$ cells $/ \mathrm{mm}^{3}$ ), the results support not delaying ART until after TB treatment. The reason for this is unclear. In the Durban study, 55\% of deaths 
occurred in those who commenced ART $<4$ weeks (case-fatality of $16 \%$ ), although the overall case-fatality was similar (12\%). ${ }^{12}$

There a significant difference in case-fatality outcomes only when compared with those who did not have ART at all. Another study in Durban showed a $29 \%$ case-fatality in HIV-TB co-infected patients who were not commenced on ART. ${ }^{13}$

Most of the deaths and defaulters occurred in those who did not have a $\mathrm{CD} 4^{+} \mathrm{T}$-cell count result recorded.

\section{Conclusion}

This health systems research showed that the management of HIV-TB in Lesotho in 2012 was not being implemented according to the current evidence-informed guidelines. The co-infected patients receiving ART had better TB outcomes than those who were not given ART. There was no statistical difference in timing of ART initiation and successful TB outcomes even after adjustment for potential confounders.

\section{Limitations}

Measurement validity was compromised as measuring the $\mathrm{CD}^{+}$ was often not possible due to lack of test reagent stocks. Mycobacterial drug susceptibilities were not known which may have influenced TB outcomes. Although statistical significance was shown with some associations, the confidence intervals were wide due to the limited sample size obtained. The limited sample size was due to resource constraints. The validity of the statistical conclusion of this study was therefore reduced. Selection bias may have occurred as HIV-TB cases from only three hospitals were included in the study sample. Although randomly selected, no hospitals from the deeply rural highlands or an urban hospital in Lesotho were included in the study sample. This study involved a secondary analysis of existing clinical data, and data in routine clinical records was occasionally incomplete. The record of having had a CD4 ${ }^{+} \mathrm{T}$-cell count or adverse drug effects was not always recorded in the TB patient registers or cards. Confounding factors that were measured were taken into account in the multivariate analysis. Due to limitations in internal validity, the generalisability of the multivariate analysiswould be limited and the TB outcomes recorded in this study may be different if a more representative sample had been used. Even though WHO guidelines indicated that those living with HIV-TB should be started on ART within two weeks of commencing TBT if $\mathrm{CD} 4^{+} \mathrm{T}$-cell count $<50$ cells $/ \mathrm{mm}^{3}$, it was apparent that Lesotho was not fully complying with this policy in 2012. As a result, it was hard to measure how the lack of compliance would have impacted on HIV-TB control.

\section{Recommendations}

This study supports the immediate initiation of ART following TB treatment in people living with HIV-TB in line with WHO policies, and this should be made a priority in southern Africa in order to optimise care in the HIV-TB co-infected. Inter-sectoral collaboration is needed to improve the integration of HIV and TB care. Improved record keeping, especially in the TB registers which are the source of primary data, is imperative for measuring programme effectiveness. More implementation research on integrating HIV-TB is needed.

Acknowledgement - We acknowledge the hospital managers of the three hospitals for allowing us to access data from their TB registers and Professor Benn Sartorius who contributed to the analysis of this research.

\section{ORCID}

Maletsatsi Lenela (DD http://orcid.org/0000-0003-2777-6469

\section{References}

1. World Health Organisation. Global tuberculosis control: WHO report 2011. Geneva: Author; 2011. Available from: http://www.who.int/tb/ publications/global_report/en/index.html

2. Maher D, Harries A, Getahun H. Tuberculosis and HIV interaction in sub-Saharan Africa: impact on patients and programmes; implications for policies. Trop Med Int Heal. 2005;10(8):734-42. https://doi.org/10.1111/tmi.2005.10.issue-8

3. Lesotho Ministry of Health and Social Welfare. Referral guidelines for TB/HIV co-management. 1st ed. Maseru: Government of Lesotho 2011.

4. Lesotho Ministry of Health and Social Welfare. National TB program annual report. Maseru: Government of Lesotho; 2011.

5. Harries AD, Zachariah R, Corbett EL, et al. Tuberculosis 3 The HIV-associated tuberculosis epidemic - when will we act? Lancet [Internet]. 2010;375(9729):1906-19. doi: 10.1016/S01406736(10)60409-6

6. Lawn SD, Myer L, Orrell C, et al. Early mortality among adults accessing a community-based antiretroviral service in South Africa: implications for programme design. AIDS. 2005;19:2141-8.

7. Naidoo K, Baxter C, Abdool Karim SS. When to start antiretroviral therapy during tuberculosis treatment. Curr Opin Infect Dis. 2014;26(1):35-42.

8. Uthman OA, Okwundu C, Gbenga $\mathrm{K}$, et al. Optimal timing of antiretroviral therapy initiation for HIV-infected adults with newly diagnosed pulmonary tuberculosis. Ann Intern Med [Internet]. 2015;163(1):32. Available from: http://annals.org/article. aspx?doi=10.7326/M14-2979

9. World Health Organization. Global tuberculosis report. Geneva: Author; 2013.

10. Statistics South Africa. Mid year population estimates. Pretoria: Author; 2010.

11. Department of Health. South Africa, Department of Health: Africa S. National tuberculosis management guidelines. Pretoria: Author; 2009.

12. Kendon M, Knight SE, Ross A, et al. Timing of antiretroviral therapy initiation in adults with HIV-associated tuberculosis: Outcomes of therapy in an urban hospital in KwaZulu-Natal. South African Med J. 2012;102(12):931-5. https://doi.org/10.7196/SAMJ.5574

13. Murphy RA, Henry S, Bushra T, et al. Low uptake of antiretroviral therapy and high mortality after tuberculosis or opportunistic infection in KwaZulu-Natal, South Africa. Int J Tuberc Lung Dis [Internet]. 2010;14(7):903-8. Available from: http://www.ncbi.nlm. nih.gov/pmc/articles/PMC3207641/pdf/nihms330295.pdf

Received: 26-04-2016 Accepted: 02-03-2017 